\title{
DESAIN DAN UJI COBA LEMBAR KERJA SISWA DENGAN PENDEKATAN SCAFFOLDING
}

\author{
Wahyuni Rizka Dharma ${ }^{1)}$, Lazulva \\ 1) Pendidikan Kimia Fakultas Tarbiyah UIN SUSKA Riau \\ Email : w.rizka93@gmail.com
}

\begin{abstract}
The main objective of the study was to examine the validy and practical level of student work sheet by a valid and practical of scaffolding approach. The study was a developing study by using 4-D (Define, Design, Develop, Disseminate). It was located in Senior High School 1 Kampar and Senior High School 2 Bangkinang City. The participants of the study were the media design expert, learning material expert, and chemistry teacher as a subject and student worksheet in the topic of the balance of chemistry by a scaffolding approach as an object. Data were collected by using a primary data from the questioner. The instruments of the data collection are the validity questioner and practical questioner. The data is analyzed by using Qualitative and Quantitative Descriptive Analysisi Technique. The findings showed the student worksheet have a percentage of validity level of $84.98 \%$ (very valid) and practical level of $87 \%$ (very practical). It can be identified that the student worksheet is accepted and can be used as a teacher learning material supplement.
\end{abstract}

Keywords: student worksheet, scaffolding, chemistry balance.

\section{PENDAHULUAN}

Ilmu kimia banyak memuat konsepkonsep abstrak seperti simbol-simbol, struktur, reaksi-reaksi dan proses-proses kimia yang terstruktur sehingga sebagian besar siswa beranggapan bahwa kimia merupakan mata pelajaran yang sulit.[1]Konsep-konsep dalam kimia secara umum tersusun berjenjang.Dalam memahami konsep yang tingkatannya lebih tinggi perlu pemahaman yang benar terhadap konsep yang lebih dasar.Selain itu untuk memahami ilmu kimia siswa harus mampu menggunakan tiga representasi yaitu makroskopik, submikroskopik, dan simbolik.

Pembelajaran saat ini diharapkan sesuai kurikulum 2013 yang menekankan pada dimensi pedagogik modern dalam pembelajaran, yaitu menggunakan pendekatan ilmiah. Permasalahan yang dihadapi di dunia pendidikan saat ini adalah belum tercerminnya pembelajaran seperti yang diamanahkan kurikulum 2013, sehingga pembelajarannya masih menekankan kognitif saja sedangkan afektif dan psikomotorik belum menjadi titik tekan dalam hasil dan proses pembelajarannya serta penilaiannya. [2]

Hasil belajar yang optimal dapat dicapai apabila peserta didik tidak hanya mengandalkan diri dari apa yang terjadi di kelas tetapi harus mampu dan mau menelusuri aneka ragam sumber belajar yang diperlukan salah satunya lembar kerja siswa, agar lebih mudah mengarahkan untuk memahami suatu konsep. Lembar kerja siswa diharapkan dapat membantu siswa lebih aktif dan mandiri sehingga dapat meningkatkan mutu belajar serta mutu pendidikan pembelajaran kimia.[3]

Beberapa media pembelajaran Kimia yang sering digunakan yaitu : Buku Materi (Paket), Lembar Kerja Siswa (LKS) dan berbagai media yang dapat diakses melalui media elektronik atau handphone. Namun 
demikian, karena siswa berada di sekolah yang menerapkan kurikulum 2013 maka proses pembelajaran yang dilakukan yaitu selalu menerapkan proses diskusi, sehingga siswa selalu melakukan diskusi dan mengkaji materi di setiap pembelajaran. Diskusi yang meliputi banyak hal sering membuat siswa hanya berdiskusi tentang mengkaji materi, sehingga siswa jarang mengerjakan latihan soal.Latihan mengerjakan soal ini sangat diperlukan, sehingga perlu adanya media pembelajaran yang berisi inti materi, contoh soal serta pengerjaannya, dan juga contoh latihan soal untuk menguji kemampuan siswa. Media ini berupa LKS, namun tampilan LKS yang dimiliki siswa ini nampaknya kurang menarik bagi siswa, salah satu penyebabnya adalah guru jarang melibatkan penggunaan LKS untuk contoh soal dalam proses diskusi.[4]

Salah satu alternatif yang dipilih adalah menerapkan pendekatan scaffolding pada lembar kerja siswa, karena pendekatan scaffolding adalahsebagai salah satu strategi pembelajaran yang memberikan bantuan (scaffold) kepada siswa dalam memecahkan masalah yang diberikan.Dengan pertolongan orang dewasa, anak dapat melakukan dan memahami lebih banyak hal dibandingkan dengan jika anak hanya belajar sendiri.[5] Sehingga di dalam lembar kerja siswa, akan diberikan bantuan - bantuan secara bertahap sampai dihilangkanya bantuan agar siswa mampu menyelesaikan tugas secara mandiri dan memahami konsep secara mandiri.

Hasil wawancara terhadap beberapa guru kimia SMA Negeri di Bangkinang dan sekitarnya diperoleh informasi bahwa selain menggunakan buku sebagai bahan ajar, guru juga menggunakan lembar kerja siswa sebagai bahan ajar tambahan.Lembar kerja siswa tersebut umumnya digunakan oleh siswa untuk mengerjakan latihan soal.Hasil analisa terhadap lembar kerja siswa tersebut diketahui bahwa isi lembar kerja siswa yang terkesan kurang menarik dan hanya berisi soal-soal saja tanpa adanya bantuan-bantuan yang membimbing dan mempermudah siswa.Sehingga kebanyakan siswa kurang minat membaca dan mempelajari isi lembar kerja siswa dan kesulitan dalam melaksanakan latihan-latihan yang diberikan oleh guru.Hal ini sesuai dengann penjelasan pada penelitian-penelitian sebelumnya tentang bahan ajar atau lembar kerja siswa.

Selain itu, pokok bahasan kesetimbangan kimia merupakan sebuah materi yang mempelajari reaksi kesetimbangan yaitu reaksi bolak-balik atau dua arah antara reaktan dan produk.Terkadang yang membuat siswa sulit memahami materi ini adalah memahami faktor-faktor yang mempengaruhi kesetimbangan serta tetapan kesetimbangan dalam reaksi tersebut. Jika guru hanya menerangkan saja, tanpa memberikan ilustrasi atau contoh maka siswa akan sulit memahaminya. Hal ini menyebabkan kebanyakan siswa kesulitan mendapatkan nilai ulangan harian yang maksimal untuk mencapai KKM ( Kriteria Ketuntasan Minimal).

Untuk itu, guru memerlukan alat yang secara langsung dapat mengarahkan pola pikir sekaligus dapat menciptakan kemandirian siswa dalam belajar. Dalam hal ini, Lembar Kerja Siswa (LKS) berperan penting untuk mengarahkan pola pikir mereka dalam menemukan konsep. Peran guru sebagai fasilitator pun dapat dimaksimalkan. Oleh karena itu, peneliti tertarik untuk mengembangkan sebuah LKS dengan pendekatan scaffolding dalam pembelajaran kesetimbangan kimia.

\section{METODE PENELITIAN}

Penelitian ini termasuk penelitian dan pengembangan (Research and Development). Penelitian ini dilaksanakan di Sekolah Menengah Atas Negeri 1 Kampar dan Sekolah Menengah Atas Negeri 2 Bangkinang Kota, karena disekolah-sekolah ini belum maksimal penerapan bahan ajar 
dalam bentuk lembar kerja siswa dan juga belum pernah dilakukan penelitian sejenis.

Penelitian ini dilaksanakan pada semester genap tahun pelajaran 2015/2016. Objek penelitian ini adalah lembar kerja siswa pada pokok bahasan kesetimbangan kimia dengan pendekatan scaffolding. Subyek dalam penelitian ini adalah pihak yang melakukan validasi terhadap produk lembar kerja siswa yang dihasilkan yaitu ahli desain media pembelajaran, ahli materi pembelajaran dan guru-guru kimia di Sekolah Menengah Atas Negeri 1 Kampar dan Sekolah Menengah Atas Negeri 2 Bangkinang Kota.

Adapun model pengembangan dalam penelitian ini adalah model pengembangan 4-D (Four D) merupakan model pengembangan perangkat pembelajaran. Model ini dikembangkan oleh S. Thagarajan, Dorothy S. Semmel, dan Melvyn I. Semmel. Model pengembangan 4D terdiri atas 4 tahap utama yaitu : (1) Pendefinisian (define), (2) Perancangan (design), (3) Pengembangan (develop) dan (4) Penyebaran (disseminate), atau diadaptasi Model 4-P yaitu Pendefinisian, Perancangan, Pengembangan dan Penyebaran. Dalam penelitian ini, akan tetapi hanya dilakukan sampai tahap ketiga yaitu sampai pada pengembangan produk (uji coba terbatas).

Teknik yang digunakan untuk mengumpulkan data dalam penelitian ini adalah angket. Angket merupakan teknik pengumpulan data yang dilakukan dengan cara memberi seperangkat pertanyaan atau pernyataan tertulis kepada responden untuk dijawabnya.[6] Angket yang digunakan dalam pengumpulan data pada penelitian ini adalah angket uji validitas dan angket uji coba terbatas.

Penilaian angket disusun berdasarkan perhitungan rating scale.Rating scale atau skala bertingkat adalah suatu ukuran subjektif yang dibuat berskala.[7] Adapun tabel skala angketnya yaitu sebagai berikut :
Tabel 1. Skala Angket

\begin{tabular}{cc}
\hline $\begin{array}{c}\text { Jawaban Item } \\
\text { Instrumen }\end{array}$ & Skor \\
\hline Sangat Baik & 5 \\
Baik & 4 \\
Cukup Baik & 3 \\
Kurang Baik & 2 \\
Tidak Baik & 1 \\
\hline
\end{tabular}

Teknik analisis data yang digunakan adalah teknik analisis deskriptif kualitatif dan teknik analisis deskriptif kuantitatif yang mendeskripsikan hasil uji validitas dan uji praktikalitas.

Untuk melakukan analisis validitas / praktikalitas lembar kerja siswa yang dikembangkan digunakan rating scale diperoleh dengan cara:[8]

1. Menentukan skor maksimal ideal

$$
\begin{aligned}
\text { Skor maksimal ideal }= & \text { banyak validator } \\
& \times \text { jumlah butir } \\
& \text { komponen } \times \\
& \text { skor maksimal. }
\end{aligned}
$$

2. Menentukan skor yang diperoleh dengan menjumlahkan skor dari masing-masing validator.

3. Menentukan persentase keidealan / kepraktisan:

$$
\text { Persentase keidealan }=\frac{\text { Skor yang diperoleh }}{\text { Skor maksimal ideal }} \times 100 \%
$$

Hasil persentase keidealan kemudian ditafsirkan dalam pengertian kualitatif berdasarkan pada tabel berikut ini.

Tabel 2. Kriteria Hasil Uji Validitas / Praktikalitas LKS

\begin{tabular}{c|c|c}
\hline No & Interval & Kriteria \\
\hline 1 & $81 \%-100 \%$ & Sangat Valid \\
2 & $61 \%-80 \%$ & Valid \\
3 & $41 \%-60 \%$ & Cukup Valid \\
4 & $21 \%-40 \%$ & Kurang Valid \\
5 & $0 \%-20 \%$ & Tidak Valid \\
\hline
\end{tabular}


Sumber: Dimodifikasi dari Riduwan

\section{HASIL DAN PEMBAHASAN}

Hasil penelitian yang dilaksanakan berdasarkan langkah-langkah prosedur pengembangan 4-D adalah sebagai berikut :

\section{Tahap Pendefinisian (Define)}

\section{a. Analisis Ujung Depan (Analisis Kurikulum)}

Dalam kurikulum 2013 dijabarkan Kompetensi Inti (KI) dan Kompetensi Dasar (KD) untuk setiap jenjang pendidikan. Pada analisis ini, hanya akan dijabarkan KI dan KD pada tingkat SMA kelas XI semester 1 yakni pada bidang pengetahuan.

Analisis yang dilakukan berdasarkan silabus mata pelajaran kimia kurikulum 2013. Hasil yang didapatkan dari tahap ini yaitu materi yang memerlukan lembar kerja siswa adalah materi kesetimbangan kimia, materi ini merupakan salah satu materi yang sulit dikelas XI MIA SMA dikarenakan mempelajari tentang reaksi kesetimbangan dan faktor-faktor kesetimbangan. Selain itu, diketahui juga masih terbatasnya lembar kerja siswa yang dapat memfasilitasi peserta didik dalam memahami konsep kesetimbangan kimia. Hal ini dikarenakan lembar kerja siswa yang digunakan di sekolah adalah lembar kerja siswa dari sebuah penerbit bukan dikembangkan oleh guru di sekolah. Hasil analisa terhadap lembar kerja siswa tersebut diketahui bahwa isi lembar kerja siswa yang terkesan kurang menarik dan hanya berisi soal-soal saja tanpa adanya bantuan-bantuan yang membimbing dan membantu siswa dalam mengerjakan soal latihan.

\section{b. Analisis Siswa}

Hasil analisis siswa yang mempelajari pokok bahasan kesetimbangan kimia yang terdapat di kelas XI MIA SMA, dimana umur siswa berada pada kisaran 15-17 tahun. Pada usia ini dinyatakan bahwa perkembangan kognitif yaitu perkembangan kemampuan (kapasitas) individu untuk memanipulasi dan mengingat informasi sampai pada tahap kematangan.

Menurut pendapat Vigotsky yang memberikan konsep utama "Zone of proximal development" (ZPD) yaitu daerah tugas-tugas yang sangat sulit untuk diatasi oleh individu secara sendirian, tetapi baru dapat dicapai apabila mendapat bimbingan atau bantuan dari orang dewasa atau teman sebaya yang lebih terampil. ZPD ini meliputi dua sisi, yaitu batas bawah dan batas atas. Batas bawah adalah tahap pemecahan masalah yang dapat dilakukan oleh remaja sendiri tanpa bantuan orang lain. Sementara batas atas adalah tahap berpikitr remaja dalam memecahkan masalah dengan bantuan orang lain (guru atau instruktur). Maka bahan ajar berupa lembar kerja siswa ini didesain dengan pendekatan scaffolding, dimana siswa diberikan bimbingan atau bantuan untuk menyelesaikan tugas-tugas yang sulit.

\section{c. Analisis Konsep}

Analisis konsep materi kesetimbangan kimia dilakukan dengan mengidentifikasikan konsep-konsep utama yang akan diajarkan sehingga mampu merangsang siswa untuk berpikir kritis melalui kegiatan-kegiatan pembelajaran yang terdapat didalam lembar kerja siswa yang akan dihasilkan. Dari hasil analisis yang dilakukan ada beberapa kompetensi dasar yang akan dikembangkan melalui indikator dan sub pokok bahasan sehingga konsep-konsep itu menjadi saling berhubungan satu sama lain membentuk peta konsep yang terdapat didalam lembar kerja siswa pada pokok bahasan kesetimbangan kimia dengan pendekatan scaffolding.

\section{Tahap Perancangan (Design)}

\section{Pemilihan Format}


Pada tahap ini peneliti merancang lembar kerja siswa pada pokok bahasan kesetimbangan kimia dengan pendekatan scaffolding . Lembar kerja siswa dirancang terdiri dari tiga bagian yaitu bagian pendahuluan, bagian isi dan bagian penutup.

\section{Bagian pendahuluan}

Bagian pendahuluan berisi deskripsi singkat, petunjuk penggunaan lembar kerja siswa dan kompetensi inti, kompetensi dasar dan indikator pembelajaran.

\section{Bagian isi}

Bagian isi terdiri dari peta konsep materi dan kegiatan belajar 1, 2 dan 3. Pada setiap kegiatan belajar dilengkapi ringkasan materi dan soal-soal latihan yang diberikan bantuan atau dorongan berupa langkahlangkah dan rumus yang digunakan agar mempermudah siswa dalam mengerjakan latihan. Adapun ringkasan materi dan contoh soal disusun berdasarkan pembelajaran saintifik yang mencakup unsur 5M yaitu : mengamati, menanya, mengumpulkan data, menalar dan mengkomunikasikan. Serta dilengkapi dengan ulangan harian beserta penilaiannya. Ulangan harian ini akan menjadi penentu pemahaman siswa terhadap materi yang diajarkan.

\section{Bagian penutup}

Bagian penutup berisi daftar kepustakaan dari berbagai sumber dalam pembuatan lembar kerja siswa dengan pendekatan scaffolding ini.

\section{Perancangan awal}

Penulisan lembar kerja siswa dibuat dengan berbagai jenis font dan ukuran font. Adapun jenis font yang digunakan seperti times new roman, comic sans ms, algerian, castellar, gill sans ultra bold, book antiqua, baskerville old face, sehingga lembar kerja siswa yang dirancang menarik minat siswa untuk mempelajarinya. Kemudian tata susunan / tata letak soal latihan disesuaikan berdasarkan pembelajaran saintifik yang mencakup unsur 5M yaitu : mengamati, menanya, mengumpulkan data, menalar dan mengkomunikasikan. Selain itu, lembar kerja siswa juga disertai dengan gambargambar dan paduan warna sehingga lembar kerja siswa dengan pendekatan scaffolding terlihat lebih menarik dari lembar kerja siswa biasanya.

\section{Tahap Pengembangan (Develop)}

Tujuan tahap ini adalah untuk menghasilkan perangkat pembelajaran yang sudah direvisi berdasarkan masukan dari pakar. Tahapan ini terdiri dari :

\section{a. Validasi lembar kerja siswa}

Validasi lembar kerja siswa dilakukan oleh 3 orang pakar atau ahli yang terdiri dari dua orang ahli materi pembelajaran dan satu orang ahli desain media yang disebut juga dengan validator.

Tahap validasi dilakukan dengan cara meminta pendapat dari pakar atau ahli untuk menilai produk yang dihasilkan, sehingga kemudian dapat diketahui kelemahan dan kekuatannya. Teknik yang digunakan adalah dengan menggunakan metode angket. Angket yang digunakan telah divalidasi oleh Validator ahli instrument seperti yang ditunjukkan oleh lembar validasi berdasarkan data pada lampiran tersebut, persentase dari penilaian yang diberikan sudah termasuk kategori "valid". Dengan demikian maka instrument angket tersebut sudah dapat digunakan untuk menilai lembar kerja siswa,

Setelah angket penilaian sudah valid, kemudian angket tersebut digunakan untuk memvalidasi lembar kerja siswa yang dikembangkan. Validasi ini bertujuan untuk melihat apakah lembar kerja siswa yang dibuat sudah layak atau tidak untuk diuji cobakan. Adapun hasil penilaian tersebut adalah sebagai berikut : 


\section{Ahli desain media}

Validasi produk oleh ahli desain media dillakukan dengan menunjukkan dan menjelaskan tentang produk media pembelajaran berupa bahan ajar yaitu lembar kerja siswa dengan pendekatan scaffoldingkepada satu orang ahli desain media yaitu bapak Dr. H. Abu Anwar M.Ag, selaku Dosen Media Pembelajaran pada jurusan Pendidikan Agama Islam dan Pendidikan Bahasa Arab di UIN SUSKA Riau. Beliau disebut sebagai validator 1 . Menurut Beliau produk ini layak digunakan sebagai media pembelajaran berupa bahan ajar di sekolah. Hasil penilaiannya dapat dilihat pada tabel 3 berikut ini :

Tabel 3. Hasil Validasi Lembar Kerja Siswa dengan Pendekatan Scaffolding oleh Ahli Desain Media Berdasarkan Komponen pada Indikator

\begin{tabular}{|c|c|c|c|c|}
\hline No. & Indikator & $\begin{array}{c}\text { Skor } \\
\text { Penilaian }\end{array}$ & $\begin{array}{c}\text { Nilai } \\
\text { Validasi }\end{array}$ & Kriteria \\
\hline
\end{tabular}

\begin{tabular}{|c|c|c|c|}
\hline $\begin{array}{l}\text { Penggunaan huruf } \\
\text { dan tulisan }(2,3 \text {, } \\
4,5,7,9,10,11 \text {, } \\
\text { 12) }\end{array}$ & 37 & $82,22 \%$ & Sangat valid \\
\hline $\begin{array}{l}\text { LKS } \\
\text { berpenampilan } \\
\text { menarik }(1,6 \text {, } \\
8,13,14,15,16 \text {, } \\
17)\end{array}$ & 33 & $82,5 \%$ & Sangat valid \\
\hline
\end{tabular}

$\begin{array}{llll}\text { Jumlah Keseluruhan } & \mathbf{7 0} & \mathbf{8 2 , 3 5 \%} & \text { Sangat valid }\end{array}$

\section{Ahli Materi Pembelajaran}

Validasi produk oleh ahli materi pembelajaran dilakukan dengan menunjukkan dan menjelaskan tentang produk media pembelajaran berupa lembar kerja siswa kepada dua ahli materi pembelajaran yaitu pertama adalah Bapak Lazulva, M.Si, selaku Dosen Pendidikan Kimia di UIN SUSKA Riau. Beliau disebut sebagai validator 2. Menurut Beliau produk ini layak digunakan untuk pembelajaran kimia.

Kemudian ahli materi pembelajaran yang kedua yaitu Ibu Miterianifa, M.Pd, selaku Dosen Pendidikan Kimia di UIN SUSKA Riau, selanjutnya beliau disebut validator 3. Menurut Beliau produk ini layak digunakan untuk pembelajaran kimia. Tetapi masih terdapat beberapa perbaikan untuk menyempurnakan lembar kerja siswa yang dihasilkan ini. Hasil penilaiannya dapat dilihat pada tabel 4 berikut ini :

Tabel 4. Hasil Validasi Lembar Kerja Siswa Dengan Pendekatan Scaffolding Oleh Ahli Materi Pembelajaran Berdasarkan Komponen Pada Indikator

\begin{tabular}{|c|c|c|c|c|c|c|}
\hline & $\begin{array}{l}\text { Variabel } \\
\text { Validitas }\end{array}$ & $\begin{array}{c}\text { Indika } \\
\text { tor }\end{array}$ & $\begin{array}{c}\text { Nomor } \\
\text { Pernya } \\
\text { taan }\end{array}$ & $\begin{array}{c}\text { Nilai } \\
\text { Validi } \\
\text { tas }\end{array}$ & ii $\underset{\text { ria }}{\text { Krite }}$ & $\begin{array}{l}\text { Kriteria } \\
\text { Tiap } \\
\text { Variabel } \\
\text { Validitas }\end{array}$ \\
\hline \multirow{4}{*}{1.} & \multirow{3}{*}{$\begin{array}{c}\text { Syarat } \\
\text { Didaktif }\end{array}$} & A & $1,2,3$ & $\begin{array}{c}96,67 \\
\%\end{array}$ & $\begin{array}{l}\text { Sangat } \\
\text { valid }\end{array}$ & \multirow{3}{*}{$\begin{array}{c}91,25 \% \\
\text { (Sangat } \\
\text { valid) }\end{array}$} \\
\hline & & B & 4,5 & $80 \%$ & $\begin{array}{l}\text { Sangat } \\
\text { valid }\end{array}$ & \\
\hline & & $\mathrm{C}$ & $6,7,8$ & 93,33 & $\begin{array}{l}\text { Sangat } \\
\text { valid }\end{array}$ & \\
\hline & \multirow{5}{*}{$\begin{array}{c}\text { Syarat } \\
\text { Konstru } \\
\text { ksi }\end{array}$} & $\mathrm{A}$ & $\begin{array}{c}9,10 \\
11\end{array}$ & $\begin{array}{c}86,67 \\
\%\end{array}$ & $\begin{array}{l}\text { Sangat } \\
\text { valid }\end{array}$ & \multirow{5}{*}{$\begin{array}{c}88,18 \% \\
\text { (Sangat } \\
\text { valid) }\end{array}$} \\
\hline \multirow{4}{*}{2.} & & B & $\begin{array}{c}12, \\
13, \\
14,15\end{array}$ & $85 \%$ & $\begin{array}{l}\text { Sangat } \\
\text { valid }\end{array}$ & \\
\hline & & $\mathrm{C}$ & 16 & $90 \%$ & $\begin{array}{l}\text { Sangat } \\
\text { valid }\end{array}$ & \\
\hline & & $\mathrm{D}$ & 17 & $100 \%$ & $\begin{array}{l}\text { Sangat } \\
\text { valid }\end{array}$ & \\
\hline & & $\mathrm{E}$ & 18,19 & $90 \%$ & $\begin{array}{l}\text { Sangat } \\
\text { valid }\end{array}$ & \\
\hline \multirow{5}{*}{3.} & \multirow{4}{*}{$\begin{array}{c}\text { Syarat } \\
\text { Pendeka } \\
\text { tan } \\
\text { Scaffolding }\end{array}$} & A & 20,21 & $70 \%$ & valid & \multirow{4}{*}{$\begin{array}{l}81,67 \% \\
\text { (Sangat } \\
\text { Valid) }\end{array}$} \\
\hline & & B & 22,23 & $85 \%$ & $\begin{array}{l}\text { Sangat } \\
\text { valid }\end{array}$ & \\
\hline & & $\mathrm{C}$ & 24 & $80 \%$ & valid & \\
\hline & & $\mathrm{D}$ & 25 & $85 \%$ & $\begin{array}{l}\text { Sangat } \\
\text { valid }\end{array}$ & \\
\hline & \multicolumn{2}{|c|}{ Rata-rata } & & \multicolumn{3}{|c|}{$87,6 \%$ (Sangat valid) } \\
\hline
\end{tabular}

\section{Data keseluruhan (ahli desain media dan ahli materi pembelajaran)}

Hasil penilaian dari ahli desain media dan ahli materi pembelajaran dijumlahkan dan dibagi dua seperti tampak pada tabel berikut. 
Tabel 5. Perhitungan Data Hasil Uji ValiditasSecara Keseluruhan

\begin{tabular}{ccc}
\hline No. & $\begin{array}{c}\text { Variabel Validitas } \\
\text { Modul }\end{array}$ & $\begin{array}{c}\text { Persentasi } \\
\text { keidealan }\end{array}$ \\
\hline 1 & Ahli Desain Media & $82,35 \%$ \\
2 & Ahli Materi & $87,6 \%$ \\
& Pembelajaran & \\
& Rata-rata & $\mathbf{8 4 , 9 8 \%}$ \\
\hline
\end{tabular}

Berdasarkan perhitungan pada tabel diatas jelas terlihat bahwa persentase keseluruhan dari penilaian para ahli adalah sangat valid. Karena berada pada rentang $81 \%$ sampai $100 \%$, sehingga lembar kerja siswa dengan pendekatan scaffolding sudah layak untuk diujicobakan ke sekolah. Namun saran dan komentar dari ahli dijadikan bahan perbaikan dalam penyempurnaan lembar kerja siswa ini.

\section{b. Uji coba praktikalitas lembar kerja siswa}

Hasil uji coba diperoleh melalui pengisian angket guna untuk mengetahui respon dari guru kimia terhadap lembar kerja siswa yang dihasilkan. Angket uji coba ini diisi oleh guru kimia setelah membaca dan memahami lembar kerja siswa dengan pendekatan scaffolding. Hasil penilaiannya dapat dilihat pada tabel 6 berikut ini :

Tabel 6. Hasil Penilaian Praktikalitas Lembar Kerja Siswa dengan Pendekatan Scaffolding Oleh Guru Kimia Berdasarkan Indikator

\begin{tabular}{llccl}
\hline No. & Indikator & $\begin{array}{c}\text { Skor } \\
\text { Penila } \\
\text { ian }\end{array}$ & $\begin{array}{c}\text { Nilai } \\
\text { Prak } \\
\text { tikali } \\
\text { tas }\end{array}$ & Kriteria \\
\hline & $\begin{array}{l}\text { Penulisan dan } \\
\text { organisasi } \\
\text { lembar kerja } \\
\text { siswa (1) }\end{array}$ & 18 & $90 \%$ & $\begin{array}{l}\text { Sangat } \\
\text { Praktis }\end{array}$ \\
1. & & & \\
Kebenaran & 32 & $80 \%$ & Praktis \\
konsep (2,3) & Kesesuain & 20 & $100 \%$ & Sangat
\end{tabular}

\begin{tabular}{|c|c|c|c|c|}
\hline & materi (4) & & & Praktis \\
\hline 4. & $\begin{array}{l}\text { Kejelasan } \\
\text { kalimat dan } \\
\text { tingkat } \\
\text { keterbacaan } \\
(5,6,7,8,9)\end{array}$ & 86 & $86 \%$ & $\begin{array}{l}\text { Sangat } \\
\text { Praktis }\end{array}$ \\
\hline 5. & $\begin{array}{l}\text { Muatan } \\
\text { kurikulum } \\
2013(10,11 \text {, } \\
12)\end{array}$ & 53 & $\begin{array}{c}88,3 \\
\%\end{array}$ & $\begin{array}{l}\text { Sangat } \\
\text { Praktis }\end{array}$ \\
\hline 6. & $\begin{array}{l}\text { Tingkat } \\
\text { keterlaksanan } \\
\text { latihan soal } \\
(13,14)\end{array}$ & 33 & $\begin{array}{c}82,5 \\
\%\end{array}$ & $\begin{array}{l}\text { Sangat } \\
\text { Praktis }\end{array}$ \\
\hline 7. & $\begin{array}{l}\text { Evaluasi } \\
\text { belajar } \\
(15,16)\end{array}$ & 35 & $\begin{array}{c}87,5 \\
\%\end{array}$ & $\begin{array}{l}\text { Sangat } \\
\text { Praktis }\end{array}$ \\
\hline 8. & $\begin{array}{l}\text { Tampilan } \\
\text { fisik lembar } \\
\text { kerja siswa } \\
\left(\begin{array}{ll}17, \quad 18, \quad 19 \\
20,21)\end{array}\right.\end{array}$ & 88 & $88 \%$ & $\begin{array}{l}\text { Sangat } \\
\text { Praktis }\end{array}$ \\
\hline & & \multicolumn{2}{|c|}{365} & \\
\hline \multicolumn{2}{|c|}{ Persentase Keidealan } & \multicolumn{3}{|c|}{ 87\% (Sangat Praktis) } \\
\hline
\end{tabular}

Berdasarkan perhitungan pada tabel diatas, didapatkan hasil bahwa media pembelajaran berupa lembar kerja siswa dengan pendekatan scaffolding sudah sangat praktis dengan kategori layak untuk diuji cobakan, jelas terlihat bahwa persentase keseluruhan dari penilaian guru pada uji coba praktikalitas adalah $87 \%$, karena berada pada rentang $81 \%$ sampai $100 \%$. Sehingga lembar kerja siswa dengan pendekatan scaffolding tidak memerlukan revisi. Namun saran dan komentar dari guru dijadikan bahan pertimbangan dalam penyempurnaan lembar kerja siswa ini.

Berdasarkan hasil penilaian yang didapatkan pada validitas dan praktikalitas, menyatakan bahwa lembar kerja siswa pada pokok bahasan kesetimbangan kimia dengan pendekatan scaffolding adalah sangat valid dan sangat praktis dengan persentase berturut-turut yaitu $84,98 \%$ dan $87 \%$.

\section{SIMPULAN}

Berdasarkan hasil penelitian dapat disimpulkan bahwa : (1) Lembar kerja siswa pada pokok bahasan kesetimbangan kimia dengan pendekatan scaffolding dinyatakan 
valid oleh ahli desain media dan ahli materi pembelajaran dengan kategori sangat valid yaitu dengan persentase $84,98 \%$. Hal ini terlihat dari persentase rata-rata analisis angket ahli desain media dan ahli materi pembelajaran berturut-turut yaitu $82,35 \%$ dan $87,6 \%$. (2) Lembar kerja siswa pada pokok bahasan kesetimbangan kimia dengan pendekatan scaffolding dinyatakan praktis oleh guru-guru kimia di sekolah dengan kategori sangat praktis yaitu dengan persentase $87 \%$.

\section{REFERENSI}

[1] Yanto, Robi., Eny Enawaty., dan Erlina. Pengembangan Lembar Kerja Siswa (LKS) Dengan Pendekatan Makroskopis-Mikroskopis-Simbolik Pada Materi Ikatan Kimia. Hlm.2. Pontianak : Universitas Tanjung Pura.

[2] Rosita, A., Sudarmin., dan P. Marwoto. Perangkat Pembelajaran Problem Based Learning Berorientasi Green Chemistry Materi Hidrolisis Garam Untuk Mengembangkan Soft Skill Konservasi Siswa. Jurnal Pendidikan IPA Indonesia. Hlm. 134, 2014. Semarang Universitas Negeri Semarang.

[3] Fahrucah R, Eren., dan Bambang Sugiarto. Pengembangan Lembar Kerja Siswa Pada Pembelajaran Kimia Sma Kelas Xi Pokok Bahasan Faktor - Faktor Yang Mempengaruhi Laju Reaksi Melalui Pendekatan Scaffolding.Unesa Journal of Chemical Education Vol. 1, No. 1. Hlm. 93. 2012. Surabaya : Universitas Negeri Surabaya.

[4] Wijayanti, Dian., Sulistyo Saputro., dan Nanik Dwi Nurhayati. 2015. Pengembangan Media Lembar Kerja Siswa (LKS) Berbasis Hierarki Konsep untuk Pembelajaran Kimia Kelas X Pokok Bahasan Pereaksi Pembatas. Jurnal Pendidikan Kimia, Vol. 4. No.2. Hlm. 15-16. 2015.Surakarta : Universitas Sebelas Maret.
[5] Agustina, Trisia. 2013. Pengaruh Pemberian Bantuan (Scaffolding) pada Aktivitas Belajar Menggunakan Model Penemuan Terbimbing Terhadap Hasil Belajar Fisika Siswa SMA. 2013. Bandar Lampung :Universitas Lampung.

[6] Triyono. Metodologi Penelitian Pendidikan. Yogyakarta: Penerbit Ombak, 2013. Hlm. 157

[7] Trianto. Mendesain Model Pembelajaran Inovatif-Progresif, Konsep, Landasan, dan Implementasinya Pada Kurikulum Tingkat Satuan Pendidikan (KTSP). Jakarta: Kencana, 2010. Hlm. 268

[8] Riduwan.Skala Pengukuran VariabelVariabel Penelitian. Bandung : Alfabeta, 2007. Hlm. 15 